\title{
The role of the distribution platform in price formation of paid apps
}

\author{
Paolo Roma *, Fabio Zambuto, Giovanni Perrone \\ DICGIM - Management E Economics Research Group, Università degli Studi di Palermo, Viale delle Scienze, 90128 Palermo, Italy
}

\section{A R T I C L E I N F O}

\section{Article history:}

Received 26 July 2015

Received in revised form 5 June 2016

Accepted 19 July 2016

Available online 25 July 2016

\section{Keywords:}

Mobile app market

Online distribution

Pricing

Electronic commerce

Multi-level data

\begin{abstract}
A B S T R A C T
In this paper we study the role of the distribution platform as an important determinant of price of paid apps. We also examine how the distribution platform influences the price implications of important developers' app-level decisions. To these purposes, we construct a hierarchical model of price formation by using an ad-hoc panel dataset consisting of top paid apps from the two major app stores, namely Apple's App Store and Google Play. Our findings show that prices of paid apps strongly depend on the platform where the apps are marketed. Specifically, the App Store is associated with lower prices for paid apps than Google Play. We find evidence that this is because the impact of cross-store differences in developer competition prevails over the impact of cross-store differences in average consumer willingness to pay. We also find that the price premiums as a return to trialability are more likely to emerge in Google Play than in the App Store, and that developers are more likely to adopt a penetration price policy in Google Play, thus implying an influence of the distribution platform on the price implications of these app-level decisions. Finally, our evidence does not confirm the argument that a more marked price reduction for paid apps embedding ads or generating revenues from other interested third parties should be observed in Google Play.
\end{abstract}

(c) 2016 Elsevier B.V. All rights reserved.

\section{Introduction}

In the very last few years, mobile software applications (apps, hereafter) have become important components of people's everyday life. As a matter of fact, the time per day spent by US consumers using apps increased by $35 \%$ in 2012, and was higher than the time spent on the web and quite close to that spent watching TV [32]. Also, recent estimates suggest that the revenue generated from customers buying and downloading apps for smartphones and tablets will step from $\$ 26$ billion in 2013 up to $\$ 77$ billion in 2017, whereas the number of downloads will increase from 102 billion to 268 billion [25,41]. Although apps for mobile devices have been around since the late 90s, the app market started soaring in 2008 when Apple introduced the application store distribution paradigm. An application store is essentially an online distribution platform from which users can download apps developed by third parties for mobile devices and operating systems (OS) supported by the platform. Nowadays two app stores undoubtedly dominate the scene accounting for almost $90 \%$ of global app downloads: Apple's App Store and Google Play [25].

While the rapid growth of the app market offers numerous business opportunities to a multitude of app developers, it also provides a great opportunity for researchers to examine various theoretical issues like innovation, entry and exit strategies, platform leadership, externalities,

\footnotetext{
* Corresponding author.

E-mail addresses: paolo.roma@unipa.it (P. Roma), fabio.zambuto@unipa.it (F. Zambuto), giovanni.perrone@unipa.it (G. Perrone).
}

and marketing mix [7]. Initial studies have mostly concentrated on app demand estimation and the factors driving such demand across major app stores $[11,24,26]$ or the determinants of app success [33,34]. In this paper, we instead focus on the role of the distribution platform in price formation of paid apps. Paid apps accounted for $75 \%$ of the revenue of app stores worldwide in 2013 and are expected to play a prominent role also in the future [41]. In addition, industry figures document that price levels of paid apps change significantly across stores, suggesting that pricing decisions could depend on the distribution platform [10].

Therefore, from a practical perspective, enhancing the understanding about the impact of the distribution platform in price formation of paid apps is clearly important to developers who have adopted the paid app business model, as it can help them fine-tune their pricing decisions to the chosen targeted platform. From a theoretical perspective, elucidating the rationale behind the potential emergence of differences in price levels across different online platforms is also particularly relevant for the literature on online price formation. In fact, although price formation across online retailers has been extensively studied in the past decade in the electronic commerce literature [6,9,13-15,27,37,40,55], the insights derived from these studies might not necessarily apply to app stores. Indeed, there exist two fundamental differences, which distinguish app stores from traditional online retailers and thus motivate our study on the role of the distribution platform in the app market.

First, online stores examined by previous studies are pure merchants who purchase from producers and resell to customers by charging a retail price based on the wholesale price set by upstream firms $[28,29]$. For this reason, the differences in price levels across stores documented 
by prior works are mostly explained by the different pricing and service policies experimented by online retailers, thus implying the existence of a significant store effect in online price formation $[6,15,16,59]$. Conversely, such practices are unlikely to be the sources of price differences across stores in the context of apps. This is because the prices to final customers are set directly by developers, who then share the revenue from each unit sold with the platform owner according to a fixed sharing rule, common to all major stores.

A second crucial difference lies in the unique relationship between the mobile OS/device market and the app market. Once consumers choose their favorite OS/mobile device (e.g., Apple or Android), they are locked in by this decision, as they rely exclusively on the sponsored platform to source their apps. ${ }^{1}$ This implies that the customer base in a given platform strictly depends on the customer base of the associated product, i.e., the mobile device and the relative OS. Different mobile device makers and/or OS providers naturally target different segments based on their product quality and marketing capabilities. In particular, with regard to the two major mobile device ecosystems, there exist several important differences between consumers accessing the App Store and those populating Google Play. Specifically, Apple targets exclusively the (loyal) high-end of the market, whereas the sales of Android devices are mostly fueled by low-end segments of the market $[3,4,17,18,26,30]$. Moreover, Apple users tend to be heavier and less tech-savvy mobile users than Android users [17,26,30] As explained later, these differences imply that app developers face significantly different consumer segments in terms of willingness to pay across different platforms $[3,4,17,18,26,30]$, while this is unlikely to be the case in traditional online stores. This is because in the latter stores consumers are not forced to bear any exclusive relationship with the distribution channel, as there is no associated product and/or platform technology locking them in. Thus, the heterogeneity in the willingness to pay of consumers buying the same item (e.g., the same electronic device brand) across two traditional online retailers, e.g., Amazon.com and Newegg.com, is much lower than in the case of consumers buying the same app in App Store and Google Play. This particular feature of the app market implies that, differently from online retailers studied in previous literature, app stores can be viewed as distinct markets where developers might be required to set different prices, even for the very same item. Therefore, the role of the distribution platform in price formation of paid apps should stem from driving forces that are different from those highlighted in previous studies, and thus, need to be unraveled.

Our paper aims at filling this important gap by investigating the role of the distribution platform as an important determinant of price of paid apps. In particular, we aim at answering the following research questions, which have never been examined before:

1) Does the distribution platform where paid apps are marketed have a direct influence on their price formation?

2) Does the distribution platform chosen for paid apps influence the price implications of certain important app-level decisions?

Therefore, the scope of this paper is to shed light on whether and how the distribution platform matters in price formation of paid apps, both via its direct influence on prices and via its moderating role of the relationships between certain important app-level decisions and app prices. To provide an answer to the above questions we compare prices of top (i.e., most downloaded) paid apps from the two most important distribution platforms, i.e., Apple's App Store and Google Play, and construct a hierarchical model of app price formation, taking into account potential non-random selection issues by means of the propensity score matching (PSM) method [50].

In detail, our contribution is twofold. With regard to the first question, we explain that the distribution platform has a direct impact on prices

\footnotetext{
${ }^{1}$ Ghose and Han [26] report that, at any given point in time, consumers usually own either Apple or Android devices.
}

emerging from two contrasting store-level forces. On the one hand, the higher average willingness to pay of consumers in the App Store, as implied by their higher levels of income and app usage and lower levels of technology consciousness, favors higher prices for paid apps in this store. On the other hand, the lower in-store developer competition favors higher prices for paid apps in Google Play, in light of the lower willingness to pay of consumers and the higher app customization costs, which make this store less attractive to developers. Results from our sample show that Google Play is associated with higher prices for paid apps, suggesting that the effect of competition is dominant. With regard to the second question, we argue and find that the distribution platform can also influence the relationships between important app-level decisions and price of paid apps. Specifically, we find that the positive effect of offering a free trial version on the price of the full paid version is more likely to emerge in Google Play, as consumers with lower willingness to pay are more sensitive to the uncertainty surrounding the app value. We also find that, differently from the App Store, the lower willingness to pay of consumers in Google Play limits developers' ability to resort to price skimming, and leads them to adopt a penetration price strategy when launching new apps. However, we do not find support for our hypothesis that the distribution platform influences the effect of the presence of alternative app revenue streams generated from advertisers or other interested third parties on the app price.

The remainder of this paper is organized as follows. In Section 2, we present our theoretical arguments and discuss the related hypotheses. In Section 3, we describe the data, the variables and the methods utilized in this paper. In Section 4, we present our empirical findings and discuss their implications. In Section 5, we discuss some robustness checks. Finally, we conclude in Section 6.

\section{Theory and hypotheses}

The central tenet of our arguments is that the distribution platform matters for price formation of paid apps in two ways. First, the chosen distribution platform - App Store vs. Google Play - has a direct impact on the price of a paid app, ensuing from several characteristics that lead to two contrasting store-level forces, i.e., cross-store differences in consumer willingness to pay and in the level of in-store developer competition. Second, the distribution platform also impacts prices indirectly, by influencing the price implications of three important developers' decisions at the app level.

\subsection{The main effect of the distribution platform on price of paid apps}

In our view, the impact of the distribution platform on price levels of paid apps may arise as a result of several relevant differences existing between the two major platforms. First, industry studies suggest that Apple's customer base can count on higher average income than Android-based devices' customer base [3,4,17,18,26,30]. Second, these studies further show that Apple consumers tend to be heavier mobile users (they spend more time on their apps) and enthusiastic early adopters of new mobile technologies [17,30]. Therefore, Apple consumers have on average more money to spend on their apps and also a greater need to improve their smartphones' functionalities and consumption experience. Third, it is recognized that Android users tend to be relatively more tech-savvy than Apple users as they are more associated with technical and computer-related jobs and they follow technology news more frequently $[26,30]$. Because of their knowledge, they tend to be more cautious and far-sighted in their purchases (for instance by comparing more alternatives), as compared with Apple users, who are instead more addicted consumers [30]. These characteristics unambiguously suggest that Apple users tend to be more prone to spend their money on apps, and thus have higher average willingness to pay than users of Google Play $[3,4,17,18,26,30]$. In turn, this should play in favor of higher prices for paid apps in the App Store. 
However, a further important difference between the two platforms is that Android OS is released under an open source license, as opposed to Apple iOS, which runs only for Apple devices. This means that Android is a more flexible system which runs on multiple devices (and target more heterogeneous customer base), but also implies the existence of greater device fragmentation and thus higher development costs, due to the need for developers in Google Play to customize apps for different smartphones to fully exploit this flexibility and reach a plethora of consumers $[1,22]$. Since development costs are fixed costs, they do not have a direct impact on price. Yet, according to the industrial organization literature [54], they may still have an indirect influence on price by affecting the level of competition. Indeed, higher development costs work as a stronger barrier to deter developers' entries in the platform. In turn, this plays in favor of milder levels of competition in Google Play because a lower number of developers will actually prefer to enter and compete in this market. Cross-store differences in the level of developer competition are further amplified by the aforementioned different willingness to pay of consumers populating the two stores. Indeed, developers are more stimulated to enter and compete in the App Store than in Google Play because they can potentially extract higher value from consumers with higher willingness to pay [46]. ${ }^{2}$ Industry figures corroborate the presence of a higher level of competition in the App Store, suggesting that developers in the App Store are almost twice as those in Google Play [38]. Such difference becomes even stronger when considering only paid apps. In fact, a larger number of developers prefer selling paid apps in the App Store [57]. As a result, the higher competition in the App Store should drive lower prices for paid apps in this store as compared with Google Play.

Summing up, the distribution platform should have an impact on the prices of paid apps, as a result of the store-related factors discussed above. On the one hand, the App Store should be associated with higher prices for paid apps than Google Play, because consumers accessing the former store tend to be wealthier, more app-addicted and less techsavvy, and thus they are on average more willing to pay for apps. On the other hand, Google Play should be the platform associated with higher prices for paid apps, as this store attracts less competition in light of the lower willingness to pay of its customers and the higher app customization costs. As there is no theoretical argument a priori to anticipate which of the two effects actually prevails, we formulate two alternative hypotheses on the overall net effect of the distribution platform, as follows:

H1a. App Store is associated with higher prices than Google Play for paid apps, due to the higher average consumer willingness to pay.

H1b. App Store is associated with lower prices than Google Play for paid apps, due to the higher level of in-store developer competition.

\subsection{The role of the distribution platform in the effect of developer decisions at the app level on paid app price}

In this section, we explain that the distribution platform can play a role in price formation of paid apps also by influencing the impact of three important developers' decisions at the app level - i.e., offering a free trial version, adopting alternative revenue streams (e.g., revenue from advertising), and choosing an introductory pricing scheme for new products - on the price of paid apps. Indeed, while the price implications of these app-level decisions have been extensively studied for information goods [20,23,36,51], little attention has been devoted to

\footnotetext{
2 This is facilitated by the fact that the entry barriers in the app market tend to be relatively modest, except for the discussed customization costs, which however play in the same direction as the consumer willingness to pay. That is, they reinforce the higher attractiveness of the App Store over Google Play, and thus induce fiercer in-store developer competition in the former store.
}

understand whether and how these implications depend on the choice of the online distribution channel. More specifically, we argue that in the app market, it is important from a pricing perspective for the chosen app-level decision to be made by taking into account the distribution platform where the paid app is marketed. In particular, the characteristics of the consumer segments developers inherit from the associated device makers and/or OS providers should be considered.

\subsubsection{The role of the distribution platform in the price effect of a free trial version release}

In general, trialability measures the extent to which potential adopters perceive that they have an opportunity to experiment with an innovation prior to committing to its usage $[2,43,49]$. Through a trial version users can test the product and resolve the uncertainty about its real value to them [56]. Also, trialability can serve to signal product quality as the knowledge that a product is available in a free trial version represents some sort of guarantee to customers. For these reasons, consumers generally pay higher price if given the opportunity to test the product before buying, consistent with the idea that they place value on reduced uncertainty surrounding the product [23].

Developers often release a free trial version associated with the paid version of their apps in both the App Store and Google Play. Our argument is that the price implications of offering a free trial version depend on the distribution platform where the paid app is marketed. We point out that consumers with different willingness to pay may have a different perception about the uncertainty surrounding the value of an app, and thus they could react differently to price strategies of developers. Consumers with more limited willingness to pay (e.g., because of the limited budget or the lower need to use apps) could perceive higher risk in buying an app of unknown value, despite the rather small price. This is because, as compared with consumers characterized by higher willingness to pay, they are more likely to realize a negative surplus when the wrong app is purchased. Moreover, for consumers with lower willingness to pay, a wrong purchase may also be more likely to preclude the opportunity to substitute the wrong app with a better alternative, given that this would require spending additional money and thus would more likely lead to a negative surplus. Therefore, the release of a free trial version able to reduce the uncertainty surrounding the app value should provide higher benefits to consumers who are in general less willing to pay. Since, higher price premiums for the full paid version are gained as a return to trialability [23], our argument implies that consumers who are in general less willing to pay should be more likely to recognize such price premiums for the full paid version to the developers that help them resolve product uncertainty by releasing a free trial version. In other words, the positive impact of the free trial release on the price of the full paid version is more likely to emerge when selling to consumers characterized by a lower willingness to pay because of the higher risks they perceive in buying an app of unknown value. As industry evidence has clearly shown that consumers have more limited willingness to pay in Google Play than in the App Store, the above considerations suggest that the positive effect of trialability on the price of the full paid version is more likely to be observed in the former store. Hence, we formulate the following hypothesis:

H2. The positive effect of trialability on the price of paid apps depends on the distribution platform. In particular, such an effect is more likely to emerge in Google Play.

2.2.2. The role of the distribution platform in the price effect of in-app advertising and other revenue streams

A considerable number of developers of paid apps seek to monetize not only from the price consumers pay to download apps, but also from enabling advertisements inside apps. For instance, several paid game apps, among others, contain third parties' ads (although with minor intensity as compared with free apps). Apps displaying ads can 
attract consumers who are interested in using the app on one side, and advertisers interested in advertising their products to users within the app on the other side. Third parties interested in app users are not limited to advertisers. Indeed, developers of apps such as social networking applications pursue the strategy of building a large user base to attract, in addition to app users, firms interested in consumer information for commercial purposes (referred to as info seekers). In this case, developers, e.g., WhatsApp Inc., may also earn from selling non-personally identifiable information [58].

The interest of third parties in advertising their products inside the app (or in acquiring app user information) naturally increases with the number of consumers utilizing the app because their audience (or the base of information) becomes larger. That is, app users exert large positive cross-side externalities on third parties. In this case a profitable pricing strategy would imply to target aggressively, i.e., subsidize, the side of users (the app users in our case) who are able to exert a larger positive externality on other side (e.g., advertisers), and monetize from the latter $[45,48,35]$. As a consequence, we should observe that, ceteris paribus, paid apps generating revenue streams from third parties interested in app users (e.g., ads-supported apps), have lower prices than those that do not exhibit such characteristic. This is because developers would subsidy app users to take advantage from the fact that a large user base will attract third parties (such as advertisers or info seekers) from which to monetize. In contrast, developers of apps that do not rely on these alternative revenue streams do not have such an incentive to reduce the price to users given that they cannot monetize from interested third parties.

We examine whether the effect of the presence of in-app advertising or other revenue streams generated from third parties interested in app users (e.g., info seekers) hinges upon the chosen distribution platform. Our argument is that the magnitude of the price reduction necessary to attract a sufficiently large user base heavily depends on the type of consumers buying that app. Indeed, the extent of the price reduction also depends on the price sensitiveness of the consumers receiving such reduction. That is, larger price reductions should be offered when these consumers are more price-sensitive, and thus less willing to pay $[21,45,48]$. As app stores feature significantly different consumers in terms of willingness to pay on average, this argument suggests that when a developer decides to monetize from in-app advertising or other revenue streams generated from third parties interested in app users, the price implications of such decisions should differ across app stores. In particular, we should expect larger price reductions, if any, for consumers in Google Play than in the App Store, given the lower consumer willingness to pay in the former store. Hence, we can formulate the following hypothesis:

H3. The negative effect of the presence of in-app advertising or other revenue streams generated from third parties interested in app users on the price of paid apps depends on the distribution platform. In particular, such an effect is more likely to emerge in Google Play.

\subsubsection{The role of the distribution platform in the introductory pricing policy}

The choice of the introductory pricing policy for new products has been extensively studied in the marketing literature $[42,44,52,53]$. When launching a new product firms can balance between two extreme pricing schemes, namely market skimming or market penetration [19, 42]. Under a skimming policy, firms initially set a high price targeting high-value customers. Then, as the product moves forward in its lifecycle, its price is gradually decreased to attract less valuable segments. In contrast, a penetration policy implies setting a low price at first to capture a large market base. Then, once a large market base is established, the price can be raised.

In the app market the existence of considerable word-of-mouth and other network effects among users should induce developers of many apps to leverage on a penetration policy to exploit the advantage of a large installed market base [20,36,51]. In this case, an app first released should have a lower price than a more mature app, ceteris paribus. That is, the price of the app should increase with the app age [52]. However, numerous successful apps have unique features that cannot be easily imitated or substituted. Furthermore, for many apps there may be users who are highly valuable. For instance, passionate gamers can certainly afford to purchase their preferred app right after the release at any price. In this case developers could prefer skimming this segment and later decrease the price to target less addicted users, due to the presence of high customer heterogeneity and product differentiation $[19,44,53]$. Under the circumstances, an app first released should instead have a higher price than an app already mature in the market, ceteris paribus. That is, the price of the app should decrease with the app age [52].

The above considerations would suggest that in the app market both pricing schemes are equally plausible, thus yielding no univocal prediction on the relationship between the age of the paid app and its price. We suggest that the pattern of the price of new apps could be better understood after taking into account the role of the distribution platform. We argue that in Google Play there could be limited room for a price skimming policy. Since price skimming aims at capturing the high end of a market, it requires the existence of a group of highly valuable consumers who are willing to pay significantly more than the others for the product. This market segment could be relatively small or less developed in Google Play, where consumers generally tend to have lower willingness to pay as compared with those in the App Store. On the other hand, price penetration could be more impactful in this platform, as users who are in general less willing to pay (i.e., the vast majority in Google Play) would respond more favorably to lower initial prices, thus facilitating the establishment of an ample consumer base. The situation is different in the App Store. In this platform consumers are more willing to pay than those in Google Play (for instance, because they are wealthier and heavier users). Thus, it is possible for a considerable number of developers to benefit from skimming high-end segments first by charging them higher prices. At the same time, other developers could also succeed by using a penetration policy when their apps feature important network externalities. Accordingly, in Google Play developers should be more likely to implement a penetration policy rather than a skimming one. Thus, in this store we should observe that, ceteris paribus, younger paid apps are on average priced lower than more mature paid apps as prices gradually increase over time under a penetration price policy. Conversely, since both penetration and skimming schemes could work effectively in the App Store, it is difficult to predict the dominance of either policy. Hence, we simply formulate the following:

H4. Developers are more likely to use a price penetration policy in Google Play than in the App Store.

\section{Data and methods}

\subsection{Data}

To test the above hypotheses, we built an ad hoc dataset by collecting data of top (i.e., most downloaded) paid apps for smartphones in the Italian version of App Store and Google Play. We recorded data from the top paid app ranking publicly available in each of these platforms on a daily basis in the period going from March 7th to May 15th, 2013 (60 observation periods in total).

Top app rankings have been utilized by prior research analyzing the app market (e.g., [11,24]). Similarly to Carare [11], we restricted our focus to the top 100 apps. There are several important reasons for why all studies consider top app rankings. First, these rankings are easily available from the app stores. Second, the insights obtained from studying successful apps, rather than average apps, can be certainly more useful to developers that are planning the development and marketing of new 
apps. Third and most important, although both App Store and Google Play count more than one million applications available for download, the actual number of apps that are displayed to consumers is much more limited. In both stores consumers have access only to web pages displaying top rankings (e.g., top free, top paid, top grossing) for all apps, top rankings within each app category or top new entries and sponsored apps. Essentially only the very top portion of the app market is actually visible to consumers. This implies that top rankings are arguably the primary source of information not only for researchers to study this novel market, but also for consumers to make their purchase decisions, as highlighted also by Carare [11]. Furthermore, besides their absolute relevance [41], we naturally restrict to the top paid apps and avoid considering top free apps (i.e., the most downloaded free apps), as our focus is to understand the role of the distribution platform in price formation of paid apps. In this respect, we are consistent with previous econometric analyses on price formation, which considered non-zero prices [8]. Similarly, top grossing rankings were also excluded, given the presence of numerous free apps in this ranking. Finally, our choice of observing apps in a time span of about two months is in line with previous studies $[11,24]$. After recording the top 100 paid apps from the two stores along the entire period of observation we obtained a rich dataset containing 11,999 observations related to 567 apps (402 apps in App Store and 165 app in Google Play, respectively), that have appeared at least once in the top paid ranking of one of the two stores during the observation period. ${ }^{3}$ By construction, our sample is an unbalanced panel dataset as more successful apps appear in the rankings more often than others.

\subsection{Variables}

\subsubsection{Dependent variable}

Our theoretical arguments look at the relationship between prices of paid apps and the distribution platform, as well as the role of the distribution platform in influencing the price implications of three app-level decisions. Hence, our dependent variable is the logarithm of the daily price (in Euros) of each app featured in the top 100 paid apps rankings of the two platforms during our period of observation. The logarithmic transformation is common in pricing literature [60-62].

\subsubsection{Independent variables}

Our H1a and H1b suggest that the distribution platform chosen for a paid app will influence its price. H1a suggests that the App Store will be associated with higher prices for paid apps than Google Play because consumers accessing the former store tend to be wealthier, more appaddicted and less tech-savvy, and thus they are on average more willing to pay for apps. In contrast, H1b predicts the opposite outcome because of the higher level of in-store competition among developers in the App Store as compared with Google Play. To test these predictions we first introduce a dummy variable, namely Store, which is equal to one if on a given day an app-store pair (i.e., an app in a given store) is observed in the top 100 paid app ranking of Google Play, zero if observed in the top 100 paid app ranking of App Store. Based on the sign of the reported coefficient on our dummy Store we can assess whether one of the two opposing effects we have theorized dominates the other, giving rise to significant differences in prices across stores. Therefore, our first set of hypotheses looks at the overall net effect of the distribution platform on the price of paid apps. However, besides providing evidence that prices of paid apps significantly differ between Apple and Google, we also provide further evidence to show that the differences captured by our dummy

\footnotetext{
${ }^{3}$ The number of observations is 11,999 instead of 12,000 because we were not able to retrieve accurate and extensive information about one app appearing only once in the top ranking of Google Play. Moreover, the number of distinct apps is actually 524. This is because there are 43 apps available in the top 100 paid apps rankings of both stores during the observation period. Nevertheless, as explained later, according to our hierarchical model of price formation we consider the app-store pairs, which are indeed 567, as our statistical units.
}

Store can be ascribed to the underlying forces we propose i.e., store-level willingness to pay and in-store developer competition. Specifically, with regard to the store-level competition, we first show that there exist significant differences in the level of in-store developer competition between the two platforms and then explicitly introduce a store-level developer competition variable in our models under the expectation that it should have a negative impact on prices. In this respect, we take advantage of the fact that in-store developer competition can vary over time because developers' entries (and exits) are very dynamic in this market and thus it is possible to measure the impact of changes in the level of developer competition on app prices.

With regard to the store-level willingness to pay, we note that such factor is very stable over time (especially as compared with app price), as it descends from strategic choices related to the type of market segments targeted by the associated device and/or OS providers. As a matter of fact, using secondary data on consumer willingness to pay for a larger time span (i.e., 2011-2014), we always observe a large and persistent gap in willingness to pay between Apple and Google users. Thus, any measure of store-level willingness to pay has almost zero variation in the sample and is extremely correlated with the dummy Store, thus making it difficult to discern its direct effect on prices from the overall net effect. Therefore, to isolate the direct effect of cross-store differences in consumer willingness to pay, we exploit the cross-sectional variation in the value of apps within each store, relying on the fact that, for information goods, price levels mostly reflect the consumer willingness to pay when the effect of other relevant factors (i.e., competition) becomes negligible $[23,51,54]$. Specifically, we consider the subsample of low value apps (defined as those belonging to the lowest price quartile within each of the two app rankings) to demonstrate that store-level consumer willingness to pay plays a role in driving cross-store differences in app prices, particularly favoring higher prices in the App Store. Indeed, for low value apps, cross-store differences in competition and the relative effect on the emergence of cross-store price differences should be considerably weakened, thus allowing a better disentanglement of the effect of cross-store differences in consumer willingness to pay. This is because, as compared with their "colleagues" in the App Store, developers in Google Play tend to concentrate more on commercializing low value (low price) apps, rather than high value (high price) apps, given that they can easily anticipate that, on average, Android users are more reluctant to pay high prices. As a consequence, while in general there exist high cross-store differences in developer competition (with the App Store displaying higher competition), when considering only low value apps the competition levels between the two stores tend to become closer. With a reduced role of cross-store differences in developer competition, our dummy Store should mostly capture the direct effect of the store-level consumer willingness to pay, if any, as this effect should emerge more strongly in this case, favoring higher prices in the App Store.

As discussed above, we use a measure of store-level competition in addition to the dummy Store. However, as the number of sales or downloads of each developer in a given store is not disclosed, we cannot compute measures of competition based on market shares. In addition, the vast majority of apps and developers are never displayed on the pages of the two stores. Therefore, it is not possible to retrieve timevarying information on the number of all developers in a platform and the number of their apps. In turn, this impedes the calculation of a Herfindahl-Hirschman Index (HHI) based on these data. To overcome this problem, we measure the extent of developer turnover in the top paid apps ranking of the store. In fact, it is straightforward that a larger turnover in the daily composition of top 100 ranking (in terms of developers) reflects fiercer competition among developers to increase download as well as higher intensity of new market entries. Note that this choice is consistent with a consolidated stream in the industrial organization literature using measures of firms' turnover in the market to reflect the level of competition [5,12,31]. To construct our measure of 
in-store competition (namely, Turnover) we compute the number of developers that never appeared in the top ranking of paid apps during our observation period over the seven days before the given day of observation. ${ }^{4}$ It is important to note that our measure of competition is even more accurate than those that could be ideally computed based on the number of apps of all developers in the store (if it were possible to compute them precisely). This is because, with a multitude of apps "invisible" to consumers, the majority of developers of such apps are never a threat to developers of top apps, and a measure based on such information would not capture the real level of competition among developers. ${ }^{5}$

To test our H2, which suggests that the positive impact of trialability on the price of a paid app is more likely to be associated with Google Play than with App Store, we retrieve information on the existence of a free trial version for the app from the descriptions provided by app developers in the given store, and introduce a dummy (Free trial version) indicating whether the developer offers a free trial version for the paid app or not, as well as its interaction with our Store dummy. ${ }^{6}$ In our H3 we maintain that the effect of the presence of in-app advertising or other revenue streams generated from third parties interested in app users (e.g., info seekers) on price should be especially evident in Google Play given the lower willingness to pay of consumers accessing this store. To test this hypothesis, we analyzed each app to check for the presence of ads inside the app, as we had no access to revenue information from third parties, e.g. advertisers. In addition, we included all apps belonging to the social networking app category. This is because, as also suggested in their service provision policies, these apps (e.g., WhatsApp) can monetize from selling (non-personally identifiable) data of a large user base to interested third parties. Accordingly, we introduce a dummy variable (Ads \& other revenue streams) equal to one if the given app contains ads inside and/or belongs to the social networking category, as well as its interaction with the dummy Store. To test our H4, which suggests that developers are more likely to adopt a penetration price policy in Google Play than in App Store, we followed the marketing literature examining penetration vs. skimming policies and recorded the release date of the app in the given store [52]. Similarly to previous studies, this allowed us to compute the time (number of days) since the app has been available for download in the given store (Time since release), i.e., the app age, and interact this variable with the dummy Store. Indeed, if developers in a store tend to adopt on average a penetration (skimming) policy, this measure should have a positive (negative) impact on prices indicating that, as apps move forward in their lifecycle, developers tend to increase (decrease) their price [52]. ${ }^{7}$

\footnotetext{
${ }^{4}$ In this respect, it is important to note that looking at the turnover over the past week helps mitigate a potential endogeneity problem due to reverse causality between observed prices and our store-level competition variable. Also, note that our results are robust even when considering the new entries of developer in the top 100 paid apps ranking during a different number of days (e.g., 5 or 10 ) before the given day of observation.

${ }^{5}$ In spite of the mentioned weaknesses of using data on the number of developers and their apps, we found that our results are robust also when using a daily HHI obtained by computing the market shares as the number of apps (both paid and free) of each developer featured in the top paid ranking of the given store on the given day divided by the total number of apps of all the developers featured in the top paid ranking of the same store on the same day.

${ }^{6}$ Note that we distinguish between proper free trial version, i.e., version offering very limited features or being time-locked, and free version, i.e. version that does not differ much from the paid version except for the presence of (more) ads. Therefore, we include a specific dummy (Free version) to control for the effect of the latter type of version, which is not related to trialability.

7 An important caveat related to testing our proposed interactions (i.e., $\mathrm{H} 2-\mathrm{H} 4$ ) is that our dummy Store embodies two store-level effects. Thus, although the distribution platform could influence the price implications of the developers' app-level decisions discussed in $\mathrm{H} 2-\mathrm{H} 4$, it might be argued such influence is due to differences in in-store developer competition rather than to consumer willingness to pay as we propose. In order to rule out this alternative explanation we also explicitly interacted these app-level decision variables with the Turnover variable. Our results showed that these interactions are never significant, and thus the difference in in-store developer competition is unlikely to be the driving forces behind $\mathrm{H} 2-\mathrm{H} 4$ (this analysis can be made available from the authors upon request).
}

Finally, in addition to the above variables of interest, we control for a number of other factors, which may influence app price formation. First, in addition to the store-level competition variable, we introduce a variable measuring competition at the app level in a given store. Indeed, different apps could have a different number of substitutes marketed by other developers in the given store. To compute this measure, we considered all the apps marketed by the developers observed in our sample. Based on this population, we computed for each app the number of (both paid and free) substitutes at a given time (Substitutes). Note that by doing so, we did not only consider the apps appearing in top 100 paid app rankings, but also those apps not appearing in the ranking, as long as they were developed and marketed by the developers present in our sample. This is consistent with our earlier argument that the major threats for an app likely come from developers that have been able to market their apps more successfully. To identify app substitutes accurately, we created 69 subcategories based on the real scope and functionalities of the given apps retrieved from the descriptions provided by developers. Also note that, by including free apps in computing the variable Substitutes, we explicitly capture the effect of the presence of free apps on the price of paid apps. We also control for the app category (we count 14 categories in our sample as indicated in Table 1), the type of developer (Developer type), i.e., whether the app provider is a firm or (group of) individual(s), the number of apps marketed by each observed developer in the given day and store (Number developer apps), and the app size in Megabyte (App size). We also control for whether in-app purchase (i.e., the opportunity to directly upgrade to additional features inside the app) is implemented for the given paid app, by introducing a dummy variable (In-app purchase). Furthermore, given that users can rate the apps they download, we recorded such information for each app to construct a measure of app quality. Both App Store and Google Play allow users to provide apps' rating on a 1-to-5 scale where 1 corresponds to the worst valuation and 5 to the best valuation. However, sometimes no rating is displayed for certain apps because the number of users who have provided a rating is too low. To cope with this issue, we construct four dummies based on the rating: low rated apps (Low app rating) category if the app rating is below 2.5 , medium rated apps (Medium app rating) category if the app rating is between 2.5 and 3.5, high rated apps (High app rating) category if the app rating is above 3.5, and a category of apps displaying no rating (No app rating). ${ }^{8}$ We also control for the extent of developer notoriety by including a dummy (Developer fame), which indicates whether the developer of the given app is worldwide established. ${ }^{9}$

Table 1 shows the descriptive statistics of the variables employed in our study. On average, prices of paid apps in Google Play are considerably higher than those in the App Store (3.41 and 1.87, respectively), and both stores display significant within-store price variation. At the same time, observed competition levels are higher in the App Store than in Google Play both at the store level (the mean of the variable Turnover is 25 in the App Store and only 5.94 in Google Play) and at the app level (the mean of the variable Substitutes is 687 in the App Store and 349 in Google Play). These figures seem to suggest that the different levels of in-store competition between the two stores could play a significant role in determining cross-store differences in price of paid apps. As for our categorical variables, Table 1 clearly suggests that the top paid apps rankings of the two stores do not display the same composition in terms of apps. Thus, price differences across the two platforms might be due to the different apps featured in the rankings

\footnotetext{
${ }^{8}$ Note that there might be endogeneity due to potential reverse causality between price and app rating. In the robustness section, with the support of instrumental variables (IV) regression, we show this is not the case in our sample.

9 Based on corporate revenue information and worldwide brand recognition we identify 22 top developers in our sample: Activision Blizzard, Adobe Systems, Apple, Autodesk, AVG Technologies, Capcom, De Agostini, Disney Interactive, Electronic Arts, Fox Digital Entertainment, Gameloft, Google, Konami, Mediaset, Namco Bandai, Research in Motion (Blackberry), Sega Sammy, Square Enix, Take-Two Interactive, TomTom International BV, Ubisoft Entertainment, Zynga.
} 
Table 1

Descriptive statistics.

Panel A: Descriptive statistics for categorical (dummy) variables

\begin{tabular}{|c|c|c|c|c|c|c|c|}
\hline \multirow[b]{2}{*}{ Variables: } & \multicolumn{3}{|c|}{ Mean (\%) } & \multirow[b]{2}{*}{ Variables: } & \multicolumn{3}{|c|}{ Mean (\%) } \\
\hline & Total & App Store & Google Play & & Total & App Store & Google Play \\
\hline Store & $50.00 \%$ & $0.00 \%$ & $100.00 \%$ & Games & $38.20 \%$ & $46.70 \%$ & $29.70 \%$ \\
\hline Free trial version & $15.63 \%$ & $8.50 \%$ & $22.77 \%$ & Healthcare \& Fitness & $2.83 \%$ & $3.67 \%$ & $2.00 \%$ \\
\hline Ads \& other revenue streams & $8.98 \%$ & $8.52 \%$ & $9.45 \%$ & Money \& Finance & $0.50 \%$ & $0.00 \%$ & $1.00 \%$ \\
\hline Free version & $31.86 \%$ & $24.20 \%$ & $39.52 \%$ & Music & $5.85 \%$ & $6.17 \%$ & $5.53 \%$ \\
\hline In-app purchase & $35.91 \%$ & $44.15 \%$ & $27.67 \%$ & News \& Info & $0.42 \%$ & $0.83 \%$ & $0.00 \%$ \\
\hline No app rating & $0.96 \%$ & $1.92 \%$ & $0.00 \%$ & Photo \& Video & $7.57 \%$ & $11.37 \%$ & $3.77 \%$ \\
\hline Low app rating & $2.43 \%$ & $4.85 \%$ & $0.00 \%$ & Social network & $2.10 \%$ & $2.17 \%$ & $2.03 \%$ \\
\hline Medium app rating & $12.93 \%$ & $18.23 \%$ & $7.63 \%$ & Themes \& Customization & $7.73 \%$ & $5.57 \%$ & $9.88 \%$ \\
\hline High app rating & $83.68 \%$ & $75.00 \%$ & $92.37 \%$ & Travel & $3.89 \%$ & $2.75 \%$ & $5.03 \%$ \\
\hline Developer type & $86.03 \%$ & $84.23 \%$ & $87.83 \%$ & TV & $0.65 \%$ & $1.30 \%$ & $0.00 \%$ \\
\hline Developer fame & $22.37 \%$ & $24.70 \%$ & $20.04 \%$ & Utility & $21.52 \%$ & $9.38 \%$ & $33.66 \%$ \\
\hline Education & $1.98 \%$ & $2.23 \%$ & $1.72 \%$ & Weather & $3.09 \%$ & $2.32 \%$ & $3.87 \%$ \\
\hline Entertainment & $3.68 \%$ & $5.55 \%$ & $1.80 \%$ & & & & \\
\hline
\end{tabular}

Panel B: Descriptive statistics for continuous/integer variables

\begin{tabular}{|c|c|c|c|c|c|c|c|c|c|c|c|c|}
\hline & \multicolumn{4}{|c|}{ Total sample } & \multicolumn{4}{|c|}{ App Store } & \multicolumn{4}{|c|}{ Google Play } \\
\hline & Mean & Std Dev & Min & Max & Mean & Std Dev & Min & Max & Mean & Std Dev & Min & Max \\
\hline App size (Mbyte) & 81.59 & 252.82 & 0.02 & 1945.6 & 108.27 & 265.56 & 0.2 & 1730.6 & 54.92 & 236.42 & 0.02 & 1945.6 \\
\hline Turnover & 15.82 & 10.92 & 2 & 45 & 25.70 & 6.13 & 16 & 45 & 5.94 & 2.42 & 2 & 11 \\
\hline Number developer apps & 23.73 & 55.26 & 1 & 480 & 29.90 & 55.02 & 1 & 354 & 17.57 & 54.81 & 1 & 480 \\
\hline Substitutes & 518.54 & 623.20 & 0 & 1665 & 687.19 & 743.12 & 0 & 1665 & 349.86 & 409.45 & 0 & 1104 \\
\hline Time since release & 575.98 & 423.14 & 1 & 1770 & 503.40 & 442.13 & 2 & 1770 & 648.57 & 390.00 & 1 & 1428 \\
\hline Price $(€)$ & 2.64 & 4.05 & 0.39 & 49.99 & 1.87 & 3.52 & 0.89 & 49.99 & 3.41 & 4.38 & 0.39 & 49.99 \\
\hline
\end{tabular}

rather than to the arguments we propose. We will carefully address this issue in the subsequent sections when discussing how matching similar apps across stores helps mitigate these potential biases. Table 2 reports the correlation matrix. First, note that the dummy Store and the storelevel measure of competition are highly correlated (Pearson correlation coefficient equal to -0.92 ). At any rate, these two variables are not introduced at the same time in the regression analyses that follow. Also note that, in such analyses, we choose the dummy Games and Medium app rating as baselines for app category and app rating variables, respectively.

\subsection{Methods}

Our unbalanced panel dataset naturally displays a multi-level structure as each observation is related to the daily price of a given app, marketed by a given developer, in a given store. Hence, observations related to the same app in the given store, as well as those pertaining to same developer in the given store are likely to be correlated. Similarly, observations in the same store could be correlated as they are exposed to common store-level factors. Therefore, we propose a four-level model to analyze the role the distribution platform in price formation of paid apps. The first level is the observation (i.e., the app in the given store on a given day); the second level is the app-store pair (i.e., the app in the given store), the third level is the developer-store pair (i.e., the developer in the given store), the fourth level is the store. Essentially, as app stores can be viewed as different markets, we structure our dataset so that observations are nested within app-store pairs, which are nested in developer-store pairs, which in turn are nested within stores. In presence of such multi-level data structure, the use of mixed linear effects regression models is usually suggested in literature [47]. As we aim at shedding

Table 2

Correlation matrix.

\begin{tabular}{|c|c|c|c|c|c|c|c|c|c|c|c|c|c|c|c|c|}
\hline & Variables & $(1)$ & $(2)$ & (3) & $(4)$ & (5) & $(6)$ & $(7)$ & $(8)$ & (9) & $(10)$ & $(11)$ & $(12)$ & $(13)$ & $(14)$ & $(15)$ \\
\hline (1) & Developer type & & & & & & & & & & & & & & & \\
\hline (2) & Developer fame & 0.22 & & & & & & & & & & & & & & \\
\hline (3) & Number developer & 0.20 & 0.51 & & & & & & & & & & & & & \\
\hline (4) & Free trial version & 0.08 & -0.04 & -0.05 & & & & & & & & & & & & \\
\hline (5) & Free version & 0.02 & -0.26 & 0.00 & -0.29 & & & & & & & & & & & \\
\hline (6) & In - app purchase & 0.23 & 0.26 & 0.26 & -0.13 & -0.05 & & & & & & & & & & \\
\hline (7) & Ads \& other revenue streams & -0.03 & -0.01 & -0.01 & -0.03 & 0.05 & 0.09 & & & & & & & & & \\
\hline (8) & Time since release & 0.04 & -0.08 & -0.03 & 0.14 & 0.13 & -0.14 & 0.09 & & & & & & & & \\
\hline (9) & App size (Mbyte) & 0.25 & 0.46 & 0.30 & -0.12 & -0.28 & 0.44 & 0.00 & -0.25 & & & & & & & \\
\hline (10) & Substitutes & 0.14 & 0.21 & 0.16 & -0.12 & -0.10 & 0.32 & -0.01 & -0.23 & 0.24 & & & & & & \\
\hline (11) & No app rating & -0.05 & -0.04 & -0.03 & -0.04 & -0.03 & -0.05 & -0.02 & -0.09 & -0.01 & -0.01 & & & & & \\
\hline$(12)$ & Low app rating & -0.12 & -0.04 & -0.02 & 0.01 & -0.05 & -0.08 & 0.14 & -0.10 & -0.07 & -0.06 & -0.02 & & & & \\
\hline (13) & Medium app rating & -0.07 & 0.28 & 0.11 & -0.11 & -0.19 & -0.04 & 0.07 & 0.03 & 0.11 & -0.03 & -0.04 & -0.06 & & & \\
\hline (14) & High app rating & 0.13 & -0.22 & -0.08 & 0.12 & 0.20 & 0.08 & -0.12 & 0.04 & -0.07 & 0.06 & -0.22 & -0.36 & -0.87 & & \\
\hline (15) & Store & 0.05 & -0.06 & -0.16 & 0.20 & 0.16 & -0.17 & 0.02 & 0.17 & -0.43 & -0.14 & -0.10 & -0.16 & -0.16 & 0.24 & \\
\hline$(16)$ & Turnover & -0.05 & 0.04 & 0.14 & -0.18 & -0.15 & 0.16 & -0.01 & -0.16 & 0.39 & 0.12 & 0.10 & 0.15 & 0.14 & -0.22 & -0.92 \\
\hline (17) & Price (dep. variable) & 0.16 & 0.14 & 0.00 & 0.24 & -0.02 & -0.16 & -0.14 & 0.24 & -0.06 & -0.30 & -0.05 & 0.00 & -0.10 & 0.34 & -0.32 \\
\hline
\end{tabular}

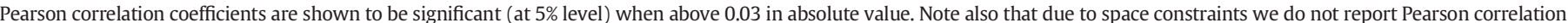

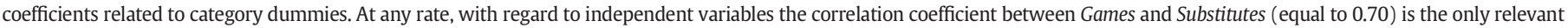

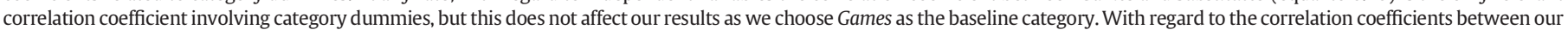
dependent variable Price and category dummies, they are all significant except that between Price and Education. 
light explicitly on the role of the store (Apple vs. Google) in price formation of paid apps, we introduce the dummy Store, the relative interaction terms and control variables at both app and developer levels as fixed effects, while treating as random the effect of the app-store and developer-store pairs. Hence, our full linear mixed effects model is:

$$
\begin{aligned}
\ln \text { price }_{\text {tijs }}= & \delta_{0}+\delta_{1} \cdot \text { Store }+\left(\delta_{2}+\delta_{3} \cdot \text { Store }\right) \cdot \text { Free trial version } \\
& +\left(\delta_{4}+\delta_{5} \cdot \text { Store }\right) \cdot \text { Two sided market }_{t i j s}+\left(\delta_{6}+\delta_{7} \cdot \text { Store }\right) \\
& \cdot \text { Time since release } t_{t i j s}+B \cdot \text { App Controls }_{t i j s} \\
& +\Gamma \cdot \text { Developer Controls } \\
t i j & +u_{j s}+r_{i j s}+\varepsilon_{t i j s}
\end{aligned}
$$

where, $r_{i j s}$ and $u_{j s}$ are the app-store and developer-store specific random effects respectively, $\varepsilon_{t i j s}$ is the error term, whereas the remaining terms are our variables of interests and controls modeled as fixed effects.

An important concern in assessing the impact of the distribution platform on prices of paid apps is related to the fact that consumers and developers might self-select in any of the two stores based on motives unknown to us. As a result, apps observed in the top ranking of App Store could be systematically different from those observed for Google Play. This might generate significant selection bias, possibly invalidating our findings. In fact, as apps in our sample are not randomly assigned to the two platforms, cross-store differences in prices could be simply due to the different types of paid apps featured in the two stores, rather than to the driving forces we have theorized. Ideally, considering exactly the same apps in the two stores would arguably solve this issue. However, only 43 apps out of 567 apps are available in the top 100 paid apps rankings of both stores during the observation period, thus not allowing a reliable econometric analysis. Therefore, in order to mitigate this selection problem and ensure a comparison of relatively similar apps across stores, we apply the Propensity Score Matching (PSM) method [50]. To avoid the biases that nonrandom assignment to treatment may generate, matching algorithms are commonly used to find a non-treated unit that is similar to a participating unit across several dimensions.

We performed the matching based on a set of both categorical as well as integer/continuous variables, and considered observations in App Store as treated units, while those in Google Play as non-treated units. ${ }^{10}$ We applied PSM within strata, by considering exact matching for app categories (which identifies the app functionalities) and app rating levels (a proxy for quality). For instance, we matched games having high rating in App Store only with games having the same rating in Google Play, and so forth. Within each of these strata, we applied the PSM and considered a set of integer/continuous covariates to further match treated and non-treated apps. We used the variable Time since release, as stores could feature apps of different maturity. Similarly, we considered the daily rank of the app to pair apps enjoying similar exposure to consumers in the two stores. After matching, our sample is reduced to 3520 observations of which half are from App Store and half from Google Play, due to the fact that we apply one-to-one matching. By construction, these matched samples have the very same composition in terms of app categories and rating level. Unreported t-tests and ANOVA analyses also confirm that matched apps in the two stores do not differ significantly in terms of age and ranking (covariates used for the matching), as well as in terms of app size. Hence, we are confident that the above matching helps mitigate potential biases in our sample arising from both consumers' and developers' self-selection in the two

\footnotetext{
${ }^{10}$ We imposed a common support (overlap condition) with no-replacement by removing treatment observations for which the propensity score was higher than the maximum or less than the minimum of the score of non-treatment observations. We also used the caliper options to select one and only one non-treated unit for each treated unit only when the propensity score difference was at most 0.001 (i.e., caliper set equal to 0.001 ).
}

stores. Finally, note that for robustness purposes we created alternative matched samples by pairing apps also based on additional covariates, ${ }^{11}$ and implemented alternative matching procedures such as coarsened exact matching. These additional analyses are fully consistent with those reported in the paper, and are available from the authors upon request.

\section{Results and discussion}

Descriptive statistics in Table 1 show that on average paid apps have higher prices in Google Play than in the App Store (3.41 versus 1.87). This difference seems inconsistent with the intuitive direct effect of store-level consumer willingness to pay, which should favor higher prices for paid apps in the App Store. Still, this does not guarantee that the lower prices in the App Store are the result of the fiercer developer competition in this store. In fact, differences in mean prices might still be driven by the different app composition in the top paid apps rankings resulting from the choices of consumers and developers that self-select in the two platforms. We have pointed out that matching apps according to their basic features should reduce (if not eliminate) such potential biases. Thus, before presenting our more formal regression models based on (1), we provide some preliminary evidence of the effect of our matching procedure on our dependent variable, i.e., the app price. T-test results reported in Table 3 show that significant differences ( $0.1 \%$ level of significance) between the average prices of the two stores emerge even when comparing matched pair of similar apps, although the magnitude of this difference is considerably reduced (from 1.54 to 0.53). ${ }^{12}$ Therefore, price differences across the two stores cannot be explained exclusively by different app composition of the two stores. Table 3 also reports the cross-store difference in the means of our two competition measures at both store and app-store levels, i.e., Turnover and Substitutes, respectively. The results clearly show that, even after matching similar apps, the two platforms differ significantly in terms of competition with the App Store displaying considerably higher competition. Overall, this preliminary analysis provides first support to our general argument that the distribution platform could influence price formation of paid apps and that the two major app distribution platforms differ in terms of in-store developer competition.

To test our hypotheses more formally we conduct a number of regression models based on the mixed linear model presented in Eq. (1). Given the potential presence of selection bias in the full sample, we run these models for the matched sample and report the results in Table 4 (the results under the full sample are qualitatively unchanged and available from the authors). With regard to our contrasting hypotheses (H1a and H1b), the first column of Table 4 shows that Google Play is associated with higher prices than App Store due to the positive (and significant) coefficient of the dummy Store $\left(\delta_{1}=0.232\right.$ and $\left.p<0.001\right)$. First, this finding confirms that price levels of paid apps depend on the store where apps are marketed. Second, it provides support to $\mathrm{H} 1 \mathrm{~b}$ against H1a. According to our arguments, this would suggest that the effect of the lower in-store competition in Google Play prevails over the opposing effect of the lower consumer willingness to pay in this store, thus leading to higher prices in this platform than in the App

\footnotetext{
11 For our main analyses we did not consider the variable App size as one of the features utilized for the matching, because the app size differ across the two stores, even for the very same apps. To give the idea, the size of TomTom Italy navigator is 404 Mbyte in App Store, whereas it is only about 29 Mbyte in Google Play. Therefore, using the size might actually distort our matching algorithm to the extent that it would not even pair the very same apps. At any rate, as we will discuss later, we created several matched samples based also on the variable App size as well as other covariates, such as Free trial version In-app purchase, and Ads E' other revenue streams, showing full robustness of our results.

12 It is noteworthy that the same result is obtained when the t-test is performed using the sub-sample of 43 apps that are present in both stores. Indeed, even with the very same top paid apps, prices in Google Play are on average higher than those in the App Store at the level of confidence of $0.36 \%(t=-2.6889)$. In spite of the weaknesses entailed by using such a small sub-sample, this result increases our confidence that our PSM approach and the resulting findings on price comparison are fully robust.
} 
Table 3

Means and relative differences before and after matching.

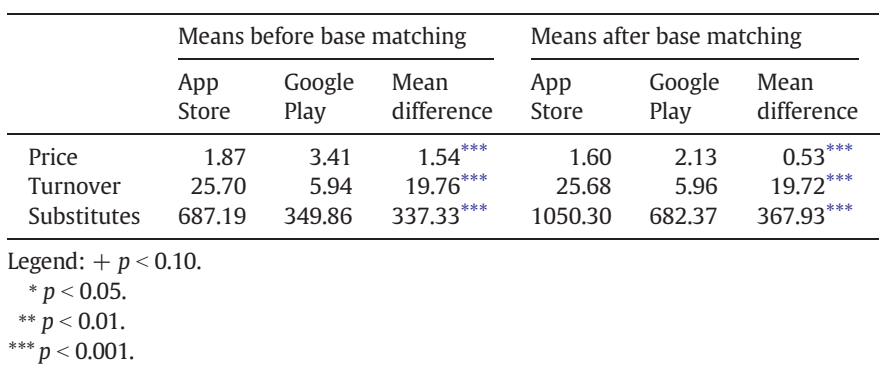

Store. To increase confidence about this interpretation, we substitute the dummy Store with our competition measure at the store level, namely Turnover. The second column of Table 4 shows that the coefficient of this variable is negative and strongly significant, substantially capturing the impact of the dummy Store. This result coupled with the highly significant gap in competition between the two platforms (shown in Table 3) provides strong support to the argument that the level of in-store competition is the major driving force behind the overall net effect of the distribution platform on prices, thus leading to higher prices in Google Play for paid apps.

Although results in the first two columns support H1b, we provide evidence that these findings emerge from a tension between the effects of the different willingness to pay of consumers in the two stores and the different in-store competition. Indeed, in columns 3-4 we show that, while in-store competition seems to explain overall price differences across stores, the differences in consumer willingness to pay (as implied by different income levels, frequency of usage and technology consciousness across stores) do actually have a direct impact on price levels of paid apps. As explained earlier, we take advantage of the cross-sectional variation in the app value in each store and demonstrate that the storelevel willingness to pay is at work in determining cross-store differences in app prices by focusing on a sample of low-value paid apps (those in the lowest price quartile within each of the two app rankings). In presence of low value (low price) paid apps, cross-store differences in developer competition should be considerably reduced, thus yielding a limited impact on cross-store price differences. The reason is that developers in Google Play (as compared with those in the App Store) tend to concentrate more on commercializing low value (low price) apps, rather than highly valuable (high price) apps, given that they can easily anticipate that, on average, Android users are more reluctant to pay high prices. This implies that when considering low value apps the competition levels between the two stores become similar. In fact, our data show that, while the average number of app substitutes in Google is roughly only $50 \%$ of that observed in Apple in the full sample, this difference significantly shrinks for the subsample of low-end apps, for which the number of substitutes in Google is almost $88 \%$ of that in Apple. Yet, while competition levels become more similar, there may still persist differences in terms of willingness to pay of consumers accessing the different platforms. Indeed, even for a low-end app, Apple users should be willing to pay more given that they are on average more affluent and heavier users.

Table 4

Distribution platform effect and its interaction with developer decisions at the app level under the matched sample.

\begin{tabular}{|c|c|c|c|c|c|c|c|c|}
\hline & $(1)$ & $(2)$ & (3) & $(4)$ & (5) & (6) & (7) & (8) \\
\hline Developer type & $\begin{array}{l}0.199^{* *} \\
(0.0696)\end{array}$ & $\begin{array}{l}0.257^{* * *} \\
(0.0748)\end{array}$ & $\begin{array}{l}-0.00619 \\
(0.00842)\end{array}$ & $\begin{array}{l}-0.0117 \\
(0.00994)\end{array}$ & $\begin{array}{l}0.185^{* *} \\
(0.0691)\end{array}$ & $\begin{array}{l}0.196^{* *} \\
(0.0697)\end{array}$ & $\begin{array}{l}0.215^{* *} \\
(0.0678)\end{array}$ & $\begin{array}{l}0.198^{* *} \\
(0.0675)\end{array}$ \\
\hline Developer fame & $\begin{array}{l}0.246^{* *} \\
(0.0783)\end{array}$ & $\begin{array}{l}0.259^{* *} \\
(0.0855)\end{array}$ & $\begin{array}{l}0.0208^{*} \\
(0.00973)\end{array}$ & $\begin{array}{l}0.0108 \\
(0.0111)\end{array}$ & $\begin{array}{l}0.243^{* *} \\
(0.0777)\end{array}$ & $\begin{array}{l}0.247^{* *} \\
(0.0785)\end{array}$ & $\begin{array}{l}0.218^{* *} \\
(0.0757)\end{array}$ & $\begin{array}{l}0.217^{* *} \\
(0.0756)\end{array}$ \\
\hline Number developer apps (Ln) & $\begin{array}{l}-0.0275 \\
(0.0192)\end{array}$ & $\begin{array}{l}-0.0358+ \\
(0.0202)\end{array}$ & $\begin{array}{l}-0.00334 \\
(0.00257)\end{array}$ & $\begin{array}{l}0.00177 \\
(0.00292)\end{array}$ & $\begin{array}{l}-0.0275 \\
(0.0191)\end{array}$ & $\begin{array}{l}-0.0272 \\
(0.0192)\end{array}$ & $\begin{array}{l}-0.0289 \\
(0.0187)\end{array}$ & $\begin{array}{l}-0.0284 \\
(0.0186)\end{array}$ \\
\hline Free trial version & $\begin{array}{l}0.0428 \\
(0.0488)\end{array}$ & $\begin{array}{l}0.0839 \\
(0.0510)\end{array}$ & $\begin{array}{l}-0.0155^{* *} \\
(0.00579)\end{array}$ & $\begin{array}{l}-0.0224^{* * *} \\
(0.00615)\end{array}$ & $\begin{array}{l}-0.0499 \\
(0.0576)\end{array}$ & $\begin{array}{l}0.0369 \\
(0.0490)\end{array}$ & $\begin{array}{l}0.0520 \\
(0.0482)\end{array}$ & $\begin{array}{l}-0.0363 \\
(0.0575)\end{array}$ \\
\hline Free version & $\begin{array}{l}-0.0650 \\
(0.0580)\end{array}$ & $\begin{array}{l}-0.0304 \\
(0.0608)\end{array}$ & $\begin{array}{l}0.000421 \\
(0.00548)\end{array}$ & $\begin{array}{l}-0.00572 \\
(0.00607)\end{array}$ & $\begin{array}{l}-0.0360 \\
(0.0581)\end{array}$ & $\begin{array}{l}-0.0644 \\
(0.0579)\end{array}$ & $\begin{array}{l}-0.0906 \\
(0.0569)\end{array}$ & $\begin{array}{l}-0.0649 \\
(0.0572)\end{array}$ \\
\hline In-app purchase & $\begin{array}{l}-0.0259 \\
(0.0521)\end{array}$ & $\begin{array}{l}-0.0338 \\
(0.0541)\end{array}$ & $\begin{array}{l}-0.00139 \\
(0.00450)\end{array}$ & $\begin{array}{l}-0.00370 \\
(0.00487)\end{array}$ & $\begin{array}{l}-0.0247 \\
(0.0514)\end{array}$ & $\begin{array}{l}-0.0243 \\
(0.0520)\end{array}$ & $\begin{array}{l}-0.0138 \\
(0.0510)\end{array}$ & $\begin{array}{l}-0.0114 \\
(0.0504)\end{array}$ \\
\hline Ads \& other revenue streams & $\begin{array}{l}-0.151 \\
(0.100)\end{array}$ & $\begin{array}{l}-0.0845 \\
(0.101)\end{array}$ & $\begin{array}{l}-0.00252 \\
(0.00619)\end{array}$ & $\begin{array}{l}-0.0121+ \\
(0.00632)\end{array}$ & $\begin{array}{l}-0.120 \\
(0.0995)\end{array}$ & $\begin{array}{l}0.0146 \\
(0.173)\end{array}$ & $\begin{array}{l}-0.163+ \\
(0.0986)\end{array}$ & $\begin{array}{l}0.0681 \\
(0.169)\end{array}$ \\
\hline Time since release & $\begin{array}{l}0.000246^{* * *} \\
(0.0000560)\end{array}$ & $\begin{array}{l}0.000168^{* *} \\
(0.0000593)\end{array}$ & $\begin{array}{l}0.00000672 \\
(0.00000585)\end{array}$ & $\begin{array}{l}0.0000161^{* *} \\
(0.00000625)\end{array}$ & $\begin{array}{l}0.000248^{* * *} \\
(0.0000554)\end{array}$ & $\begin{array}{l}0.000243^{* * *} \\
(0.0000559)\end{array}$ & $\begin{array}{l}0.0000848 \\
(0.0000666)\end{array}$ & $\begin{array}{l}0.0000891 \\
(0.0000663)\end{array}$ \\
\hline App size (Ln) & $\begin{array}{l}0.0391^{* *} \\
(0.0148)\end{array}$ & $\begin{array}{l}0.0198 \\
(0.0146)\end{array}$ & $\begin{array}{l}0.000554 \\
(0.00196)\end{array}$ & $\begin{array}{l}0.00409+ \\
(0.00217)\end{array}$ & $\begin{array}{l}0.0385^{* *} \\
(0.0147)\end{array}$ & $\begin{array}{l}0.0396 * * \\
(0.0148)\end{array}$ & $\begin{array}{l}0.0430^{* *} \\
(0.0146)\end{array}$ & $\begin{array}{l}0.0430^{* *} \\
(0.0146)\end{array}$ \\
\hline Substitutes (Ln) & $\begin{array}{l}-0.0585^{* *} \\
(0.0209)\end{array}$ & $\begin{array}{l}-0.0756^{* * *} \\
(0.0223)\end{array}$ & $\begin{array}{l}0.0000464 \\
(0.00254)\end{array}$ & $\begin{array}{l}0.00371 \\
(0.00306)\end{array}$ & $\begin{array}{l}-0.0602^{* *} \\
(0.0207)\end{array}$ & $\begin{array}{l}-0.0583^{* *} \\
(0.0209)\end{array}$ & $\begin{array}{l}-0.0592^{* *} \\
(0.0204)\end{array}$ & $\begin{array}{l}-0.0603^{* *} \\
(0.0202)\end{array}$ \\
\hline High app rating & $\begin{array}{l}0.0706 \\
(0.0461)\end{array}$ & $\begin{array}{l}0.0763+ \\
(0.0441)\end{array}$ & $\begin{array}{l}0.00595 \\
(0.00694)\end{array}$ & $\begin{array}{l}0.00820 \\
(0.00755)\end{array}$ & $\begin{array}{l}0.0692 \\
(0.0460)\end{array}$ & $\begin{array}{l}0.0683 \\
(0.0462)\end{array}$ & $\begin{array}{l}0.0751 \\
(0.0458)\end{array}$ & $\begin{array}{l}0.0709 \\
(0.0457)\end{array}$ \\
\hline Store & $\begin{array}{l}0.232^{* * *} \\
(0.0521)\end{array}$ & & $\begin{array}{l}-0.0317^{* * *} \\
(0.00650)\end{array}$ & & $\begin{array}{l}0.173^{* *} \\
(0.0553)\end{array}$ & $\begin{array}{l}0.243^{* * *} \\
(0.0530)\end{array}$ & $\begin{array}{l}0.209^{* * *} \\
(0.0508)\end{array}$ & $\begin{array}{l}0.174^{* *} \\
(0.0547)\end{array}$ \\
\hline Turnover (Ln) & & $\begin{array}{l}-0.0345^{* * *} \\
(0.00767)\end{array}$ & & $\begin{array}{l}-0.00354 \\
(0.00233)\end{array}$ & & & & \\
\hline Free trial version $\times$ Store & & & & & $\begin{array}{l}0.305^{* *} \\
(0.102)\end{array}$ & & & $\begin{array}{l}0.259^{*} \\
(0.101)\end{array}$ \\
\hline Ads \& other revenue streams $\times$ Store & & & & & & $\begin{array}{l}-0.246 \\
(0.210)\end{array}$ & & $\begin{array}{l}-0.300 \\
(0.205)\end{array}$ \\
\hline Time since release $\times$ Store & & & & & & & $\begin{array}{l}0.000436^{* * *} \\
(0.000102)\end{array}$ & $\begin{array}{l}0.000420^{* * * *} \\
(0.000102)\end{array}$ \\
\hline App category dummies & Yes & Yes & Yes & Yes & Yes & Yes & Yes & Yes \\
\hline $\mathrm{N}$ & 3520 & 3124 & 1446 & 1283 & 3520 & 3520 & 3520 & 3520 \\
\hline Developer-store obs & 262 & 244 & 126 & 117 & 262 & 262 & 262 & 262 \\
\hline App-store obs & 347 & 322 & 169 & 158 & 347 & 347 & 347 & 347 \\
\hline Wald test $-\mathrm{p}$ value & 0.0000 & 0.0000 & 0.0000 & 0.0076 & 0.0000 & 0.0000 & 0.0000 & 0.0000 \\
\hline
\end{tabular}

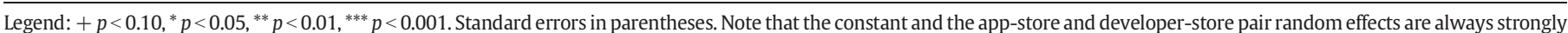
significant. Also, no app rating and low rating dummies are not reported as they display no observations in the matched sample. 
Thus, if the role of the distribution platform actually emerges from the trade-off between these two factors, the positive impact of the dummy Store should be mitigated in this subsample of apps or eventually revert as this dummy should mostly capture the direct effect of the store-level consumer willingness to pay in this case. Results in column 3 confirm this as the coefficient of the dummy Store becomes significant and negative when we run our mixed model for the subsample of low valuable apps. This implies higher prices in the App Store in this case as the cross-store differences in consumer willingness to pay would predict. The marginal role of competition in presence of low valuable apps is confirmed by observing that our measures of competition at the app level and store level (i.e., Turnover and Substitutes) are never significant in columns 3-4. Thus, in the case of low-end apps price differences across the two platforms seem to be more ascribable to different store-level consumer willingness to pay than to different in-store developer competition. This set of evidences demonstrates that the impact of the distribution platform on app prices emerges as the result of a trade-off between the effect of differences in consumer willingness to pay and the differences in in-store competition.

Columns 5-8 of Table 4 report the results for our second set of hypotheses predicting how the distribution platform influences the role of some important developers' decisions at the app level in price formation of paid apps. Specifically, in the fifth column, we add the interaction term between the dummy Store and the dummy Free trial version to the model in column 1 . First, note that in column 1 the coefficient of the dummy Free trial version was not significant, suggesting that on average trialability does not imply any price premium for the full paid version. After introducing the interaction term, the coefficient of this dummy, which now reflects the marginal change in price due to trialability in the App Store, is still not significant. However, the coefficient of the interaction term, which instead reflects the marginal change in price in Google Play due to trialability, is largely significant (at the $1 \%$ level) with a positive sign $\left(\delta_{3}=0.305\right)$, thus supporting our $\mathrm{H} 2$, which suggests that the impact of a free trial version on the price of the full paid version is more likely to be associated with Google Play. As we have argued, consumers in Google Play perceive higher risks in buying an app of unknown value than consumers in the App Store due to their lower willingness to pay. Thus, they seem to be willing to recognize a price premium to developers offering a free trial version to resolve the uncertainty surrounding the value of the paid version.

In the sixth column we add the interaction term between the dummy Store and the dummy Ads \& other revenue streams to our baseline model shown in column 1 (where the latter variable was not significant). We find that the coefficients of the latter dummy and its interaction term with the distribution platform are both not significant. Therefore, $\mathrm{H} 3$ is not confirmed in our sample, and apps generating revenue from third parties interested in app users (e.g., advertisers) do not seem to be associated with significantly different prices across the two platforms.

In the seventh column we add the interaction term between the dummy Store and the variable Time since release to the baseline model in column 1 . The coefficient of this variable was shown to be strongly significant with a positive sign in column 1 , which suggested that, on average, developers increase prices as apps move forward in their lifecycle, consistent with the adoption of a penetration price policy. However, after adding the interaction term, the coefficient on the variable Time since release, which now reflects the marginal change in price in the App Store due to an increase in the app age, is no longer significant. Conversely, the interaction of this variable with the dummy Store, which now reflects the marginal change in price in Google Play due to an increase in the age of the app, is significant with a positive sign $\left(\delta_{7}=0.0004\right.$ and $\left.p<0.001\right)$. This result supports H4, by showing that price penetration is more impactful in Google Play than in App Store, arguably because the segment of consumers characterized by high willingness to pay could be relatively less developed in the former platform to allow the adoption of price skimming scheme. The last column of Table 4 reports our full model including all three interaction terms and shows full consistency with the results in the previous models.

At this point, it is important to recall that the results in Table 4 are based on a subsample obtained by matching apps according their basic characteristics. Therefore, one could argue that the results on the interactions between the distribution platform and app-level decisions might be still biased by the fact the two rankings display different composition in terms of percentage of free trial version, app embedding ads, and so forth. Nevertheless, even after refining our matching procedure by exactly matching also for all app-level decisions variables (e.g., observations of apps offering a free trial version in App Store matched only with observations of apps offering free trial version in Google Play, and so forth), our findings remain unchanged in spite of a considerable reduction in the number of observations (from 3520 to 1520$).{ }^{13}$

\section{Robustness checks and further discussion}

In this section, we briefly discuss the results of additional analyses we conducted to test the robustness of our findings. The details of all the following robustness checks are available from the authors. First, our results are qualitatively unchanged when eliminating those apps featured in the top paid app ranking sporadically (e.g., less than three or four occurrences) to ensure comparison among apps of similar success. Our second extension addresses potential endogeneity concerns related to time-varying app characteristics. Specifically, while in the models above we control for unobserved app quality by means of app rating, we do not control for the potential effect of mobile app trend due to advertising or online word-of-mouth. As we do not have access to explicit information about the advertising expenditures or the extent of word-of-mouth, we use a proxy that reflects the mobile app trend over time. Specifically, we use the tool Google Trend provided by Google, which provides a weekly index on a 0-100 scale of search popularity of words on Google search engine in specific geographical regions. We recorded such weekly index during our period of observation by searching the exact name of all the apps in our sample. Given the popularity of Google search engine, this measure reflects the trend of an app in a given period, as a higher index is the result of greater knowledge and interest about the product, which, in turn, is likely to be the consequence of more effective advertising and online word-ofmouth over time. While being not significant, this new variable does not change our main results. Our findings are also robust when we include one dummy for each day of observation to account for the effect of trends common to both app stores and all observed apps.

Finally, endogeneity concerns might emerge also from reverse causality in the relationship between price and app rating. Indeed, the rating of an app might be affected by the price of the same app as a higher price might create higher expectations of consumers, who will be more likely to complain about product flaws and provide lower ratings to the given app. To address this concern, we perform instrumental variables (IV) regression models, where we use, as instruments for the app-level rating, the above weekly popularity index, which has been shown not to influence the price at all, and more importantly, the average rating of all the apps (except the considered app) marketed by the developer in the given store until the given day. We refer to the latter measure as the developer rating. However, it is important to note that app stores do not compute and display any developer rating to consumers, they only display app ratings. The app rating is the official mechanism provided by app stores through which consumers can express their level of satisfaction upon using an app, and thus the mechanism through which app quality can be publicized in order to increase consumers' trust. As such, it is the app rating (and not our ad-hoc measure of developer rating) that can potentially have direct influence on

\footnotetext{
13 The analysis under this refined matching procedure is available from authors upon request.
} 
consumers' willingness to pay and in turn the app price. Indeed, the fact that no developer rating is displayed to consumers considerably reduces the chances that our measure will have a direct effect on prices [39], thus making it a suitable instrument. The impact of our measure on price, if any, will only be indirect, i.e., via the app rating. The rationale is that a developer who has historically marketed apps capable of generating a high level of user satisfaction (i.e., highly rated apps) apps is more likely to commercialize an app capable meeting the favor of users (i.e., a highly rated app) than a developer that has historically marketed poorly rated apps. Indeed, the fact that a developer has received higher ratings than other developers for all other marketed apps suggests that this developer possesses better capabilities to commercialize apps that fit customers' needs than developers who are received lower ratings. The impact of our measure of developer rating on app rating is indeed shown to be strongly significant (about 1\% level of significance) from our first stage IV regression. More importantly, as both exogeneity test and the Sargan-Hansen overidentification test (which evaluates the statistical validity of instruments) are insignificant, we can be confident that our findings are not affected by potential endogeneity concerns due to the app rating variable. At any rate, the findings are robust even under the IV regression model.

\section{Conclusions}

In this paper, we have contributed to the literature on price formation in online markets by examining the unique role of online distribution platform, specifically App Store vs. Google Play, in price formation of paid apps. We have argued that differences in price levels across different stores emerge as a result of the different consumer segments and market conditions facing developers in different app stores.

In detail our findings are as follows. First, price levels of paid apps strongly depend on the targeted distribution platform, and specifically Google Play is associated with higher prices on average than App Store for paid apps. The platform effect emerges as a result of contrasting factors. On the one hand, the higher consumer willingness to pay in the App Store, as implied by their higher income and frequency of usage and lower technology consciousness, plays in favor of higher prices for paid apps in this store. On the other hand, the lower competition in Google Play, as implied by the lower willingness to pay of its customers and by the higher customization costs in this store, pushes in the opposite direction. Our findings suggest that in general differences in developer competition at the store level seem to be more influential in determining different prices across the two stores than differences in average consumer willingness to pay. Further confirming the existence of a trade-off, we find that price differences across stores are actually reversed for the restricted subsample of low value apps. Second, our findings suggest that the distribution platform heavily impacts on the price implications of two important app-level decisions made by developers. Specifically, we find that price premiums on the full paid version of the app as a return to the provision of a free trial version are more likely to be observed in Google Play, where consumers are more likely to suffer from product value uncertainty given their more limited willingness to pay. Also, the distribution platform appears to be important for the introductory pricing policy used when launching new apps. In this respect, we find developers are more likely to use a penetration price policy in Google Play, whereas they possibly use both penetration price and price skimming strategies in App Store. The rationale is that the segment of highly valuable consumers could be relatively less developed in Google Play to favor the adoption of a price skimming scheme. Finally, no evidence supports the claim that the decision to monetize from third parties interested in app users (e.g., advertisers) should yield a larger price reduction in Google Play than in App Store as a result of the lower willingness to pay of consumers accessing the former store.

These findings offer several remarkable implications for more informed decisions in the app market. A primary implication of our findings is that app developers need to fine-tune their pricing decisions to the targeted store, as different platforms imply different types of consumers, different app customization costs, and ultimately also different levels of developer competition. Also, they need to take into account the role of the distribution platform when making app-level decisions, especially those related to free trial version release and introductory price for new apps. Indeed, the price implications of such decisions depend on the distribution platform. Finally, our findings help increase distribution platform owners' awareness on the role of store-level factors in price formation and rethink their strategies to attract both users and developers.

We expect that many researchers will devote themselves to the study of the app market given its growing popularity. Accordingly, we believe that there is large room for further investigating the role of the distribution platform. For instance, the same questions posed in this paper could be addressed by using a modeling approach. Also, to complement our empirical study, it would be interesting to investigate whether developer choices related to app characteristics are influenced by the store choice, thus going beyond their mere price implication as done here. Further research could also examine the factors guiding developers in the choice of the platform when launching a new app. Specifically, this direction could provide answers to questions such as whether to launch the new app only in one store, which store to target first, whether to make simultaneous entry, and the relative rationale and performance implications of such choices.

\section{References}

[1] K. Abrosimova, How much does it cost to make iPhone, iPad and android apps? 2014 May 28. Accessed December 11, 2015 http://yalantis.com/blog/iphone-ipadandroid-app-development-cost/.

[2] R. Agarwal, J. Prasad, The role of innovation characteristics and perceived voluntariness in the acceptance of information technologies, Decision Sciences 28 (3) (1997) 557-582.

[3] App Annie, App Annie index - Japan overtakes USA, 2012 Accessed December 11, 2015 http://s3.amazonaws.com/files.appannie.com/blog/pdf/App+Annie + Index + Nov+ 2012+Report.pdf.

[4] App Annie, App Annie index - 2014 retrospective, 2014 Accessed December 11, 2015 https://s3.amazonaws.com/files.appannie.com/reports/App-Annie-Index2014-Retrospective-EN.pdf?mkt_tok=3RkMMJWWfF9wsRonvK3BZKXonjHpfsX67 04rX6G\%2BIMI\%2F0ER3fOvrPUfGjI4DTMVnI\%2BSLDwEYGJlv6SgFSrfEMbFl3rg PUxU\%3D.

[5] J.R. Baldwin, P. Gorecki, The Dynamics of Industrial Competition: A North American Perspective, Cambridge University Press, Cambridge, UK, 1998.

[6] M.R. Baye, J. Morgan, P. Scholten, Temporal price dispersion: evidence from an online consumer electronics market, Journal of Interactive Marketing 18 (4) (2004) 101-111.

[7] K.J. Boudreau, Let a thousand flowers bloom? An early look at large numbers of software app developers and patterns of innovation, Organization Science 23 (5) (2012) 1409-1427.

[8] E. Brynjolfsson, C.F. Kemerer, Network externalities in microcomputer software: an econometric analysis of the spreadsheet market, Management Science 42 (12) (1996) 1627-1647.

[9] E. Brynjolfsson, M.D. Smith, Frictionless commerce? A comparison of internet and conventional retailers, Management Science 46 (4) (2000) 563-585.

[10] Canalys, Android apps are too expensive, 2012 February 23. Accessed December 11, 2015 http://www.canalys.com/newsroom/android-apps-are-too-expensive.

[11] O. Carare, The impact of bestseller rank on demand: evidence from the app market, International Economic Review 53 (3) (2012) 717-742.

[12] R.E. Caves, Industrial organization and new findings on the turnover and mobility of firms, Journal of Economic Literature 36 (4) (1998) 1947-1982.

[13] R.K. Chellappa, R.G. Sin, S. Siddarth, Price formats as a source of price dispersion: a study of online and offline prices in the domestic U.S. airline markets, Information Systems Research 22 (1) (2011) 83-98.

[14] S.-H. Chun, J.-C. Kim, Pricing strategies in B2C electronic commerce: analytical and empirical approaches, Decision Support Systems 40 (2) (2005) 375-388.

[15] K. Clay, R. Krishnan, E. Wolff, D. Fernandes, Retail strategies on the web: price and non-price competition in the online book industry, The Journal of Industrial Economics 50 (3) (2002) 351-367.

[16] E.K. Clemons, I.H. Hann, L.M. Hitt, Price dispersion and differentiation in online travel: an empirical investigation, Management Science 48 (4) (2002) 534-549.

[17] Comscore, The U.S. mobile app market, 2014 Accessed December 11, 2015 https:// www.comscore.com/Insights/Presentations-and-Whitepapers/2014/The-US-Mobile-App-Report.

[18] Comscore, The global mobile report: how multi-platform audiences \& engagement compare in the US, Canada, UK and beyond, 2015 Accessed December 11, 2015 https://www.comscore.com/Insights/Presentations-and-Whitepapers/2015/TheGlobal-Mobile-Report. 
[19] J. Dean, Pricing policies for new products, Harvard Business Review 28 (6) (1950) 45-53.

[20] J.-P.H. Dubé, G.J. Hitsch, P.K. Chintagunta, Tipping and concentration in markets with indirect network effects, Marketing Science 29 (2) (2010) 216-249.

[21] T. Eisenmann, G. Parker, M.W. Van Alstyne, Strategies for two-sided markets, Harvard Business Review 84 (10) (2006) 1-11.

[22] J. Evans, Android vs. iOS development: fight! 2013 Accessed December 11, 2015 http://techcrunch.com/2013/11/16/the-state-of-the-art/.

[23] J.M. Gallaugher, Y. Wang, Understanding network effects in software markets: evidence from web server pricing, MIS Quarterly 26 (4) (2002) 303-327.

[24] R. Garg, R. Telang, Inferring app demand from publicly available data, MIS Quarterly 37 (4) (2013) 1253-1264.

[25] Gartner, Gartner says mobile app stores will see annual downloads reach 102 billion in 2013, 2013 September 19. Accessed December 11, 2015 http://www.gartner. com/newsroom/id/2592315.

[26] A. Ghose, S.P. Han, Estimating demand for mobile applications in the new economy, Management Science 60 (6) (2014) 1470-1488.

[27] N. Granados, A. Gupta, R.J. Kauffman, Designing online selling mechanisms: transparency levels and prices, Decision Support Systems 45 (4) (2008) 729-745.

[28] A. Hagiu, Merchant or two-sided platform? Review of Network Economics 6 (2) (2007) 115-133.

[29] R. Chen, E. Gal-Or, P. Roma, Opaque distribution channels for competing service providers: Posted Price vs. Name-Your-Own-Price Mechanisms, Operations Research 62 (4) (2014) 733-750

[30] T. Hixon, What kind of person prefer an iPhone, 2014 Accessed December 11, 2015 http://www.forbes.com/sites/toddhixon/2014/04/10/what-kind-of-person-prefersan-iphone/\#1f6c86ce3e5a25279ff83e5a.

[31] S. Hymer, P. Pashigian, Turnover of firms as a measure of market behavior, The Review of Economics and Statistics 44 (1) (1962) 82-87.

[32] S. Khalaf, Mobile Apps: We Interrupt this Broadcast, 2012 December 5. Accessed December 11, 2015 http://blog.flurry.com/default.aspx?Tag=Television.

[33] G. Lee, T.S. Raghu, Determinants of mobile apps' success: evidence from the App Store market, Journal of Management Information Systems 31 (2) (2014) 133-170.

[34] P. Roma, D. Ragaglia, Revenue models, in-app purchase, and the app performance: Evidence from Apple's App Store and Google Play, Electronic Commerce Research and Applications 17 (2016) 173-190.

[35] S. Li, Y. Liu, S. Bandyopadhyay, Network effects in online two-sided market platforms: a research note, Decision Support Systems 49 (2) (2010) 245-249.

[36] H. Liu, Dynamics of pricing in the video game console market: skimming or penetration? Journal of Marketing Research 47 (3) (2010) 428-443.

[37] Y. Liu, J. Feng, K.K. Wei, Negative price premium effect in online market - the impact of competition and buyer informativeness on the pricing strategies of sellers with different reputation levels, Decision Support Systems 54 (1) (2012) 681-690.

[38] T. Louis, How much do average apps make? 2013 Forbes. August, 10. Accessed December 11, 2015 http://www.forbes.com/sites/tristanlouis/2013/08/10/howmuch-do-average-apps-make/.

[39] M. Luca, Reviews, Reputation, and Revenue: The Case of Yelp.com, Harvard Business School Working Paper, 2016.

[40] D. Lucking-Reiley, D. Bryan, N. Prasad, D. Reeves, Pennies from ebay: the determinants of price in online auctions, The Journal of Industrial Economics 55 (2) (2007) 223-233.

[41] I. Lunden, Gartner 102B app store downloads globally in 2013, \$26B in sales, 17\% from in-app purchases, 2013 September 19. Accessed December 11, 2015 http:// techcrunch.com/2013/09/19/gartner-102b-app-store-downloads-globally-in-201326b-in-sales-17-from-in-app-purchases/.

[42] V. Mahajan, E. Muller, F.M. Bass, New product diffusion models in marketing: a review and directions for research, Journal of Marketing 54 (1) (1990) 1-26.

[43] G.C. Moore, I. Benbasat, Development of an instrument to measure the perceptions of adopting an information technology innovation, Information Systems Research 2 (3) (1991) 192-222

[44] P.M. Noble, T.S. Gruca, Industrial pricing: theory and practice, Marketing Science 18 (3) (1999) 435-454.

[45] G. Parker, M. Van Alstyne, Two-sided network effects: a theory of information product design, Management Science 51 (10) (2005) 1494-1504.

[46] M.E. Porter, Competitive Strategy: Techniques for Analyzing Industries and Competitors, Free Press, New York, NY, 1980.

[47] S.W. Raudenbush, A.S. Bryk, Hierarchical Linear Models: Applications and Data Analysis Methods, Sage Publications Inc., Thousand Oaks, CA, 2002.

[48] J.C. Rochet, J. Tirole, Platform competition in two sided markets, Journal of the European Economic Association 1 (4) (2003) 990-1029.

[49] E.M. Rogers, Diffusion of Innovations, Free Press, New York, NY, 1983.

[50] P. Rosenbaum, D. Rubin, Reducing bias in observational studies using subclassification on the propensity score, Journal of the American Statistical Association 79 (387) (1984) 516-524.
[51] C. Shapiro, H. Varian, Information Rules: A Strategic Guide to the Network Economy, Harvard Business School Press, Cambridge, MA, 1999.

[52] M. Spann, M. Fischer, G.J. Tellis, Skimming or penetration? Strategic dynamic pricing for new products, Marketing Science 32 (2) (2015) 235-249.

[53] G.J. Tellis, Beyond the many faces of price: an integration of pricing strategies, Journal of Marketing 50 (4) (1986) 146-160.

[54] J. Tirole, The Theory of Industrial Organization, The MIT Press, Cambridge, MA, 1988.

[55] R. Venkatesan, K. Mehta, R. Bapna, Understanding the confluence of retailer characteristics, market characteristics and online pricing strategies, Decision Support Systems 42 (3) (2006) 1759-1775.

[56] X. Wei, B. Nault, Experience information goods: “version-to-upgrade”, Decision Support Systems 56 (2013) 494-501.

[57] M. Wilcox, Which App Store Should You Use? Vision Mobile, 2014 (Accessed June 11, 2015. http://www.developereconomics.com/which-app-stores-should-you-use/.

[58] J.R. Williams, Mobile Computing: Predictions on Sustainable Advantage, Research Showcase Paper 541, Tepper School of Business, Carnegie Mellon University, 2009.

[59] Y. Yao, J. Zhang, Pricing for shipping services of online retailers: analytical and empirical approaches, Decision Support Systems 53 (2) (2012) 368-380.

[60] P. Roma, F. Zambuto, G. Perrone, Price dispersion, competition, and the role of online travel agents: Evidence from business routes in the Italian airline market, Transportation Research Part E 69 (2014) 146-159.

[61] P. Roma, F. Zambuto, G. Dominici, An empirical analysis of online price dispersion in the Italian airline industry, International Journal of Electronic Marketing and Retailing 6 (4) (2015) 339-358.

[62] P. Roma, G. Dominici, Understanding the price drivers of successful apps in the mobile app market, International Journal of Electronic Marketing and Retailing 7 (2) (2016) 159-185

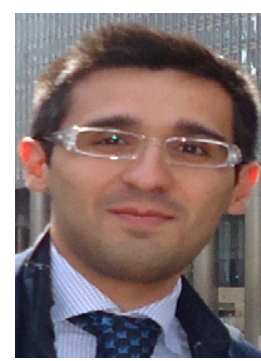

Paolo Roma is an Assistant Professor of Marketing at the University of Palermo, Italy. He received his $\mathrm{Ph} . \mathrm{D}$. in Industrial Engineering and Management from the same University in 2009. He has been a visiting scholar at the University of California at Davis, University of Pittsburgh, and Toulouse School of Economics. Dr. Roma's research focuses on topics at the interface between marketing and operations management, such as online distribution channel management, online pricing, mobile app market, innovative business models on the Internet. Outlets of Dr. Roma's research include Operations Research, Production and Operations Management, International Journal of Production Economics among others.

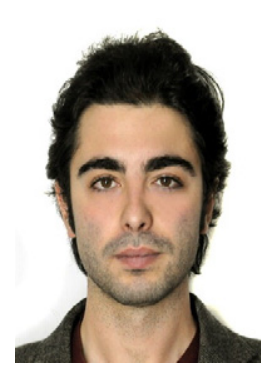

Fabio Zambuto is a Post-Doctoral Research Fellow at the University of Palermo, Italy. He received his Ph.D. in Industrial Engineering and Management from the same University in 2014. He has been a visiting scholar at the Rensselaer Polytechnic Institute, USA. Dr. Zambuto's research focuses on strategic management and innovation. Outlets of Dr. Zambuto's research include Advances in Strategic Management, Managerial and Decision Economics among others.

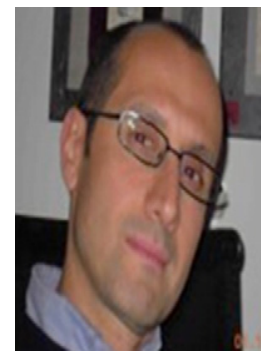

Giovanni Perrone is a Full Professor of Business and Management Engineering at the University of Palermo, Italy. He has received his Ph.D. in Industrial Engineering in 1994 from the same University. He has been visiting scholar at MIT in 1993, visiting scientist at Aachen Technical University in 1994 and visiting professor at North Carolina State University in 1996-97. He is a member of the board of EurOMA (Europen Operations Management Association), AilG (Italian Association of Engineering Management), PNICube (The Association of Italian Incubator). The scientific activity of professor Perrone is focused on operations and innovation management He is a co-author of about 130 publications mainly within international journals and conference proceedings. 